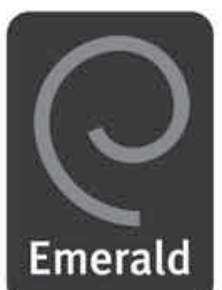

\title{
November 2004
}

\section{Dual Publication: Emerald's Response}

We respect the right of the author to pursue this kind of study and have extended our full cooperation, including personal conversations between the author and one of our Directors.

We accept that explicit notice of dual publication should have been published alongside each article and regret any inconvenience as a result of that notice not being given. However, the activity was not without the knowledge of the authors as implied, as all reasonable steps were taken by MCB to contact and inform the authors of our intent to publish their article in another journal.

During the period 1989 to 2000 , articles considered to be of particular merit were occasionally published within another MCB journal where it was felt that their content would be of interest or benefit to the additional journal audience. Today, Emerald relies on comprehensive databases and search engines to provide wide dissemination of noteworthy articles.

In addition, when certain journals were acquired, previously published articles were used to help where we had inherited a significant delay in the despatch schedule. Again, we acknowledge that explicit notice of re-publication should have been made when it took place in these circumstances. To put this into context, the re-publication of articles in Clinical Performance in Quality Healthcare was from the British Journal of Clinical Governance, with which it was subsequently merged (within 12 months) and for which there was an identified subscriber overlap between the two journals of five customers world-wide. We have conducted our own research and will contact all those customers affected.

In order to explain to researchers and users working with Emerald content now, and in the future, that certain articles were published twice in different journals, Emerald is adding a "note" to the SGML (which is the header information) following the abstract, which will explain where else the paper has been published. This work will be completed by the end of 2004 .

There has been no deliberate dual publication since 2001. There are two accidental instances of dual publication to our knowledge in recent times - one a book review and one an article that appeared in Equal Opportunities International. This is a journal owned and published by Barmarick Publications. The content is not owned by Emerald, but is currently hosted on the Emerald website.

To reiterate, our policy is not to practise dual publication. We may, however, occasionally re-publish an article with the author's consent and full attribution. These circumstances may include a themed collection or review issue, a landmark paper/classic article or an anniversary issue of a notable journal.

Publishing practices at Emerald today emphasise our communication and service levels to customers. We are dedicated to building lasting relationships with librarians and faculty members and to focusing on the future. In 2002 Emerald was awarded the Charleston Advisor Award for customer support. We regularly survey our authors and library customers to gauge their views on how we serve their needs, and the results are very positive. Ongoing communication with our stakeholders provides valuable feedback to improve the service to our author, library, researcher and user communities.

Once again, we apologise for any inconvenience caused to our authors and customers and fully acknowledge that attribution should have been given. We now have an explicitly stated policy and are correcting the SGML of affected articles.

If you were affected by any of the issues covered within this response, please contact:

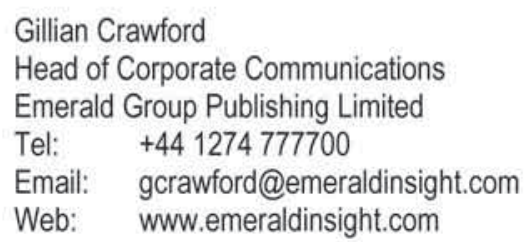

